\title{
Multimorbidity and its social determinants among older people in southern provinces, Vietnam
}

\author{
Ninh Thi Ha ${ }^{1 *}$, Ninh Hoang Le', Vishnu Khanal ${ }^{2}$ and Rachael Moorin ${ }^{2}$
}

\begin{abstract}
Background: Developing countries are poorly equipped for health issues related to ageing populations making multimorbidity challenging. As in Vietnam the focus tends to be on single conditions. Hence little is known about burden of multimorbidity. This study aimed to examine the prevalence and the determinants of multimorbidity among older people in Southern Vietnam.

Methods: A cross-sectional study was conducted in two provinces of Southern Vietnam with a sample of 2400 people aged 60 years and older. The presence of chronic disease was ascertained by medical examination done by physicians at commune health stations. Information on social and demographic factors was collected using structured questionnaire. Univariate and multivariable logistic regression analyses were used to examine the factors associated with multimorbidity.

Results: Nearly $40 \%$ of older people had multimorbidity. Currently not working, and healthcare utilisation were associated with higher prevalence of multimorbidity. Living in urban areas and being literate were associated with lower prevalence of multimorbidity.

Conclusion: The study found a high burden of multimorbidity among illiterate, especially those living in rural areas. This highlights the need for targeted community based programs aimed at reducing the burden of chronic disease.
\end{abstract}

Keywords: Developing country, Multimorbidity, Older people, Social determinants

\section{Background}

Vietnam has experienced a remarkable change in demographic structure in recent decades. Life expectancy at birth increased from 66 years in 1990 to 72.8 years in 2009 [1]. The proportion of older population was $6.7 \%$ in 1979 to $9.0 \%$ in 2009 and has been estimated to reach to $16.6 \%$ in 2029 and $26.1 \%$ in 2049 [1, 2]. As a consequence of ageing of the population, there is a need for better understanding of the health status of older Vietnamese particularly in term of burden of chronic diseases so that appropriate responses to future needs of healthcare services can be developed.

Chronic diseases have been shown to be major causes of morbidity and mortality, accounting for $66 \%$ of the overall disease burden in men and $77 \%$ in women $[3,4]$. Chronic

\footnotetext{
* Correspondence: ninh.ha05@gmail.com

'Institute of Public Health, 159 Hung Phu Street, District 8, Ho Chi Minh City, Vietnam

Full list of author information is available at the end of the article
}

disease among older people has been considered in many studies in Vietnam but these studies have focused on quality of life and daily care aspects $[5,6]$. To our knowledge, the only one study investigating the prevalence of multimorbidity in Vietnam among adults aged 25-64 years old found a prevalence of $5.1 \%$ among men and $9.3 \%$ among women [7], however this study did not report prevalence in the elderly. Given the finding that the population of Vietnam is moving towards ageing, the prevalence of multiple chronic conditions is expected to increase and will tend to predominate in the older age groups. Since those with multimorbidity have a higher demand on healthcare services and increased healthcare costs [8], a better understanding of the burden of multimorbidity and its related factors among older people in Vietnam will provide evidence to estimate future demand for healthcare and aid in determining where health promotion programs should be targeted. This study aimed to examine the prevalence of

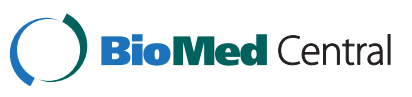

(C) 2015 Ha et al. This is an Open Access article distributed under the terms of the Creative Commons Attribution License (http://creativecommons.org/licenses/by/4.0), which permits unrestricted use, distribution, and reproduction in any medium, provided the original work is properly credited. The Creative Commons Public Domain Dedication waiver (http:// creativecommons.org/publicdomain/zero/1.0/) applies to the data made available in this article, unless otherwise stated. 
multimorbidity as well as its associated factors among older people living in Southern provinces of Vietnam.

\section{Methods}

\section{Settings and participants}

The Southern Vietnam includes around 32.2 million population divided into two main areas namely the South East and the Mekong River Delta [9]. The proportion of population aged 60 years and older is approximately $10 \%$ in both areas [9]. In 2010, the poverty rate was $2.3 \%$ in the Southeast, in the Mekong River Delta it was six times higher (12.6\%), while the poverty rate of whole country was $10.7 \%$ [9].

The health system in Vietnam consists of 4 levels: the national level with the Ministry of Health and central hospitals; the provincial level with the Provincial Department of Health and provincial hospitals; the district level with district health centres and district hospitals; and the communal level with commune health stations. Commune health stations provide primary healthcare services including preventive and treatment services and conducting national targeted health programs for people living in their catching areas. People receive diagnoses and routine care at the commune health station and are transferred to tertiary hospitals if needed [10].

\section{Study design and sampling}

This population-based study was conducted among older people aged 60 years and older residents of Dong Nai in South East and Vinh Long in Mekong River Delta during September-October, 2010. Eligible participants were selected through multi-stage sampling. In the first stage, two districts in each province, one in urban and one in rural, were selected randomly. In the second stage, five communes were randomly selected from the list of communes in each district. From an updated list of household having people aged 60 years and older in each commune, 120 households were randomly selected for visiting. In each selected household, interviewers recruited randomly one older person for the study. To minimise the potential bias, all the older people living in the selected households, except visitors, were included in the list as being eligible for selection. Ninety-seven participants were absent at the time of conducting the survey and a further 26 were unwilling to participate. These potential participants were replaced with those from the nearest households having older people at same age and gender. The participation rate was $95 \%$ which minimised participation bias in our study. A total sample of 2400 people aged 60 years and older was generated from the sampling strategy. Eligible participants were invited for interview and clinical examination in the commune health stations.

Ethical approval for the study protocol was obtained from the Institutional Review Board of Institute of Hygiene and Public Health, Ho Chi Minh City, Vietnam. All the participants of the study were provided with an explanation about the purpose of the study to avoid confusion with routine care they may have in their commune health stations. Participants were also informed about their right to not participate or withdraw from the study any time. If any inability to participate in this study that would not disadvantage them in their treatment and care at the commune health station. A written informed consent was obtained from all participants before conducting interviews.

\section{Instruments and data collection}

The questionnaire included social demographic, and health related information including disease/morbidities the participants reported. The data collection was conducted by face-to-face interview using a structured questionnaire. The information about social demographic characteristics of the participants was gained via interviews at commune health stations by trained health staff familiar with the type of data they were collecting. The presence of chronic disease was determined by medical examination and chart review by general practitioners (GP). This was augmented (but not replaced) by an audit of prescriptions where participants self-reported a previous diagnosis of chronic disease. Thus, only those having medically documented chronic disease or currently receiving pertinent prescribed medications were classified as having chronic disease. All the participants were provided travel costs and services offered by the study were free of charge. All the activities for data collection were organised separately from a routine care work. Both interviewers and general practitioners were provided the training in interviewing skills, purpose of the study and their roles in the study before conducting data collection.

\section{Dependent variables}

Information was collected about the following six broad groups of conditions: cardiovascular (including hypertension), digestive system (including liver), respiratory (including chronic obstructive pulmonary disease and tuberculosis), arthritis (including osteoarthritis), genitourinary, and diabetes. Individuals identified as having at least two of the conditions of interest were considered as living with multimorbidity [11].

\section{Independent variables}

A number of factors were included as independent variables such as age, sex, marital status, education, and place of residence [5]. All participants were categorised into three age groups: 60-69 years, 70-79 years, and 80+ years. Marital status was grouped into two groups: married/cohabiting, and single/divorced/separated/widowed. Literacy was based on self-report and categorised as illiterate and literate. Place of residence was divided into urban and rural in accordance to the local administrative classification. 
Working status was categorised into currently working (still working in fields, or self-business or others for earning) and not working basing on the self-reporting of participants. Health behaviours were smoking status (never smoked and ever smoke) and alcohol intake (never alcohol and ever alcohol). Basic activities for daily living (ADLs) were assessed through the question "do you need any help for: (i) going to toilet (ii) getting dressed (iii) washing yourself and (iv) eating? Responses were categorised as need assistance for ADLs if the participants answered yes to any one of the options [12]. Weight and height were measured by health staff at the commune health stations to calculate body mass index. This was subsequently categorised into three groups according to the $\mathrm{WHO}$ recommendation for the Asian population: $<18.5 \mathrm{~kg} / \mathrm{m}^{2}$ underweight; $18.5-$ $23 \mathrm{~kg} / \mathrm{m}^{2}$ normal; > $23 \mathrm{~kg} / \mathrm{m}^{2}$ overweight/obesity [13]. Healthcare utilisation was defined as the number of contacts with general practice, the number of medication prescriptions, and the number of referrals, categorised as yes if the participants reported using the healthcare services at least once over last week [14].

\section{Statistical analysis}

Post-stratification weights were used in all analysis to adjust for under sampling in gender and place of residence in accordance with respective strata from national demographic data [9]. Data were presented with mean and standard deviation (SD) for continuous variables and with proportions for categorical variables. Univariate logistic regression models were used to examine the association between potential factors and the presence of multimorbidity (dichotomized "one chronic condition or none" vs. "at least two chronic conditions") [11]. Variables that were statistically significant $(p$-value $<0.05)$ were further examined in multivariable logistic regressions through backward elimination. All variables were examined for interaction and multicollinearity before entering the logistic regression model. All analyses were performed using STATA 13.0.

\section{Results}

The study included 2400 participants; the characteristics and prevalence of multimorbidity of the population studied are presented in Table 1. The mean age of participants was 72.6 years (SD 8.3 years). The majority was literate, $55.3 \%$ married, and $70.6 \%$ not working. Alcohol intake and smoking were not common (less than $20 \%$ of participants) and only $6.5 \%$ of older people reported that they needed assistance for basic activities for daily living. Underweight and overweight accounted for more than a half of the sample and nearly $30 \%$ of respondents reported using healthcare service at least once in the last week. Chronic disease was present in $76.7 \%$
Table 1 Demographic and socioeconomic characteristics of the study population

\begin{tabular}{|c|c|c|c|}
\hline \multirow[t]{2}{*}{ Characteristics } & \multicolumn{2}{|c|}{ Sample } & Weighted percentage \\
\hline & N & $\%$ & $\%(95 \% \mathrm{Cl})$ \\
\hline
\end{tabular}

Mean age in years (SD) 72.6 (8.3)

Age group (years)

$\begin{array}{llll}60-69 & 913 & 38.0 & 36.9(34.9-39.1) \\ 70-79 & 936 & 39.0 & 38.7(36.6-40.8) \\ 80+ & 551 & 23.0 & 24.4(22.5-26.3)\end{array}$

Gender

Males

Females

$834 \quad 34.8 \quad 41.8(41.7-41.7)$

Marital status

Married/cohabiting

Single/ Divorced/ Widowed

Literacy

Illiterate

$466 \quad 19.4$

$20.6(19.0-22.3)$

Literate

193480.6

$79.4(77.6-80.9)$

Working status

Current working

70

Not working

169570.6

34.5 (32.4-36.5)

Place of residence

Rural

1200

50.0

69.9 (69.9-69.9)

Urban

$1200 \quad 50.0$

$30.1(30.1-30.1)$

Alcohol intake

Never alcohol

Ever alcohol

1952

81.7

77.0 (75.4-78.7)

Smoking

Never smoked

18.2

$23.0(21.3-24.6)$

Ever smoked

1930

80.5

$77.1(75.3-78.2)$

BMI $\left(\mathrm{kg} / \mathrm{m}^{2}\right)$

Underweight $(<18.5)$

$584 \quad 24.3$

$25.9(24.1-27.8)$

Normal weight (18.5 to 23)

$1148 \quad 47.8$

$48.8(46.7-51.0)$

Over weight/obesity ( $>=23$ )

$668 \quad 27.8$

$25.3(23.5-27.1)$

Basic activities for daily living

No need of assistance

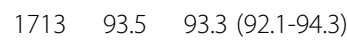

Needs assistance

$155 \quad 6.5 \quad 6.7(5.7-7.9)$

Healthcare utilisation

$\begin{array}{llll}\text { No } & 1698 & 70.7 & 71.2(69.2-73.2) \\ \text { Yes } & 702 & 29.3 & 28.8(26.8-30.8)\end{array}$

Presence of chronic disease

None

$55923.3 \quad 20.7(19.1-22.5)$

One chronic disease

$900 \quad 37.5 \quad 37.7(35.6-39.8)$

Multimorbidity 
of the sample with $37.7 \%$ having only one condition and $39.2 \%$ classified as living with multimorbidity.

Univariate logistic models showed that the prevalence of multimorbidity was significantly different across age groups, gender, marital status, education, working status, place of residence, need assistance for basis activities, and using healthcare services (Table 2). The prevalence of multimorbidity was significantly more common in the

Table 2 Univariate associations between independent variables and multimorbidity

\begin{tabular}{|c|c|c|c|}
\hline \multirow[t]{2}{*}{ Characteristics } & \multicolumn{3}{|c|}{ Multimorbidity } \\
\hline & $\%$ & OR $(95 \% \mathrm{Cl})$ & $p$ \\
\hline \multicolumn{4}{|l|}{ Age group (years) } \\
\hline $60-69$ & 36.9 & 1 & 0.03 \\
\hline $70-79$ & 43.4 & $1.3(1.1-1.6)$ & \\
\hline $80+$ & 45.9 & $1.4(1.1-1.8)$ & \\
\hline \multicolumn{4}{|l|}{ Gender } \\
\hline Males & 38.6 & 1 & \\
\hline Females & 43.8 & $1.2(1.03-1.5)$ & 0.02 \\
\hline \multicolumn{4}{|l|}{ Marital status } \\
\hline Married/cohabiting & 39.9 & 1 & \\
\hline Single/ Divorced/ Widowed & 44.0 & $1.2(0.99-1.4)$ & 0.06 \\
\hline \multicolumn{4}{|l|}{ Literacy } \\
\hline Illiterate & 51.7 & 1 & \\
\hline Literate & 39.0 & $0.6(0.5-0.7)$ & $<0.001$ \\
\hline \multicolumn{4}{|l|}{ Working status } \\
\hline Current working & 37.9 & 1 & \\
\hline Not working & 43.6 & $1.3(1.04-1.5)$ & 0.01 \\
\hline \multicolumn{4}{|l|}{ Place of residence } \\
\hline Rural & 45.9 & 1 & \\
\hline Urban & 31.6 & $0.5(0.4-0.6)$ & $<0.001$ \\
\hline \multicolumn{4}{|l|}{ Alcohol intake } \\
\hline Never alcohol & 41.7 & 1 & \\
\hline Ever alcohol & 41.1 & $0.9(0.7-1.2)$ & 0.82 \\
\hline \multicolumn{4}{|l|}{ Smoking } \\
\hline Never smoked & 41.5 & 1 & \\
\hline Ever smoked & 41.8 & $1.01(0.8-1.2)$ & 0.91 \\
\hline \multicolumn{4}{|l|}{ BMI $\left(\mathrm{kg} / \mathrm{m}^{2}\right)$} \\
\hline Underweight $(<18.5)$ & 42.7 & 1 & \\
\hline Normal weight (18.5 to 23 ) & 40.9 & $0.9(0.7-1.2)$ & 0.6 \\
\hline Over weight/obesity $(>=23$ ) & 42.3 & $1(0.8-1.2)$ & 0.9 \\
\hline \multicolumn{4}{|l|}{ Basic activities for daily activity } \\
\hline No need of assistance & 40.9 & 1 & \\
\hline Needs assistance & 51.5 & $1.5(1.1-2.2)$ & 0.01 \\
\hline \multicolumn{4}{|l|}{ Healthcare utilisation } \\
\hline No & 39.3 & 1 & \\
\hline Yes & 47.2 & $1.4(1.1-1.6)$ & 0.001 \\
\hline
\end{tabular}

older age groups than in the younger age group, $45.9 \%$ among 80 years or older and $43.4 \%$ among $70-79$ years old vs. $36.9 \%$ among $60-69$ years old $(p=0.03)$. It was also significantly more frequently observed among females than males, 43.8 vs. $38.6 \%$ ( $p=0.02)$, respectively. Prevalence of multimorbidity was significantly lower among literate participants than their counterparts (39 vs. $51.7 \%, p<0.001)$, significantly higher among those not working compared with currently working (43.6 vs. $37.9 \%$, respectively), lower among those living in urban than in rural (31.6 vs. $45.9 \%$, respectively), and higher among those who needed assistance for ADL compared with those who did not (51.5 vs. $40.9 \%$, respectively). Prevalence of multimorbidity was also positively associated with utilising healthcare services over the last week.

Results of the multivariate logistic regression analysis are presented in Table 3. While age, gender, and assistance for ADL had a crude association with multimorbidity these factors were not significant after adjusting for other variables in the model. In contrast, literacy, working status, place of residence and healthcare utilisation remained independently associated with multimorbidity. Being literate (OR $0.6895 \%$ CI 0.54-0.85), and living in urban areas (OR 0.52; 95\%CI 0.43-0.62) were independently associated with a lower likelihood of multimorbidity. Whereas, not currently working (OR 1.42 95\%CI 1.16-1.74), healthcare utilization within the previous week (OR 1.39; $95 \%$ CI 1.14-1.69) was independently associated with increased likelihood of multimorbidity.

\section{Discussion}

This study is the first to provide an overview of the magnitude and socioeconomic correlates of multimorbidity among older adults in Vietnam. In ours study nearly $40 \%$ of participants were ascertained to be living with multimorbidity. This result is in line with that of a study in Australia [15], but lower than that of a study in older people in rural Bangladesh [16]. It is also lower than that of a recent systematic review of studies mostly conducted

Table 3 Backward multiple logistic regression analyses of significant factors associated with multimorbidity among older people

\begin{tabular}{llll}
\hline Characteristics & \multicolumn{3}{l}{ Multimorbidity } \\
\hline & OR & $95 \% \mathrm{Cl}$ & $p$ \\
\hline $\begin{array}{l}\text { Literacy } \\
\quad \text { Literate vs. illiterate }\end{array}$ & 0.68 & $0.54-0.85$ & 0.001 \\
$\begin{array}{l}\text { Working status } \\
\quad \text { Not working vs. current working }\end{array}$ & 1.42 & $1.16-1.74$ & 0.001 \\
$\begin{array}{l}\text { Place of residence } \\
\quad \text { Urban vs. rural }\end{array}$ & 0.52 & $0.43-0.62$ & $<0.001$ \\
$\begin{array}{l}\text { Healthcare utilisation } \\
\quad \text { Yes vs. No }\end{array}$ & & & \\
\hline
\end{tabular}


in developed countries where the prevalence of multimorbidity among older people ranged from $55 \%-98 \%$ [8]. Such discrepancies may be due to the scope of the datasets; the differences in the age groups included in these studies, and methods used to assess the prevalence of disease $[11,17]$. In addition, there is variation in the number and type of chronic diseases that are considered as multimorbidity by researchers. Regardless of these discrepancies in the definition of multimorbidity, our finding of higher prevalence than expected using existing literature in Vietnam [7] is important since multimorbidity is associated with disability, poor quality of life and higher need of health care utilisation, which put strain on healthcare systems [18]. Thus, a more context specific and up to date assessment of prevalence in Vietnam focused on older people in rural areas provides important information for planning of health services. In addition, since previous evidence suggests that chronic diseases are often diagnosed at critical or late stage in Vietnam as regular clinical or laboratory examination for early diagnosis is not a common practice [1], accurate estimates of prevalence obtained through studies such as ours are integral to the development of strategies to alleviate the considerable financial burden due to costly treatment for households caused by multimorbidity.

We found that the burden of multimorbidity varied according to socioeconomic factors. Women had significantly higher proportion of multimorbidity than men, however the difference was not significant when adjusted for other variables, indicating that other factors associated with multimorbidity are confounded by gender. This is an important distinction, since when evaluating independent factors associated with an outcome it is important to consider confounding. However, when determining which demographic group to focus on in the preventative or therapeutic space confounding is interpreted differently. Thus in our study the prevalence of multimorbidity being higher in women (regardless of why this is occurring, women per se or factors associated with women) has implications for the provision and burden on health services. The gender differential has been shown to exist in a previous study among adults in Vietnam [7] and other countries [8, 19]. Women tend to have longer life expectancy and worse health status compared with men, and women also differ from men in terms of social and biological factors [20]. This implies the need of more attention for women's health and higher demand in healthcare for the population. Our study also agrees with previous studies showing that age is associated with multimorbidity $[19,21-23]$ and while confounded as per the discussion above this is still an important finding for planning of health services. Multimorbidity was significantly less common among literate people even adjusting for other variables showing that it is an independent factor and one that would be important to target in the preventative space. Studies conducted in Northern Vietnam [5, 7, 24] and other developing countries $[16,21]$ indicated that people with better education have less risk of chronic diseases. Education empowers an individual with knowledge and skill thus educated people can be more able to access health promotion information, and adopt healthy lifestyle [25]. Education can also shape job opportunities and earning potential, and influence living standards and healthcare [26].

Our study observed a significantly higher prevalence of multimorbidity in rural settings after adjusting for other variables. Other studies have shown the association between multimorbidity and place of residence, but with a lower prevalence in a rural area [20, 21]. Those studies conducted in a wide range of age groups that may explain the inverse association. This is a very important finding for our study as it shows that in the context of elderly Vietnamese, the rural populations are particularly at risk and pose a high and growing burden to the health care system. Healthcare utilisation was positively associated with multimorbidity. This finding was not unexpected and in line with other studies exploring the relationship between multimorbidity and utilisation of healthcare in South Africa [21], Catalonia [27], The Netherlands [14] and Europe [20]. The findings are likely to be due to the poorer general health of those living with multimorbidity; however there could also be some reverse causation bias whereby a high frequency of medical consults leads to more health conditions diagnosed. Regardless of the true nature of the relationship with the expected rise in ageing population in the coming decades, the result implied that more extensive health resources will be required [14].

Multimorbidity is common among older people and associated with healthcare utilisation that calls for a need of reviewing the organisation of healthcare services to meet the challenges of societies with a rapid increase in older population. Since developing countries are less prepared for health issues related to ageing population, more efforts should be allocated to educate primary healthcare workers and amend healthcare system in responding to the increase in multimorbidity, especially in rural areas. Our study indicates that in Vietnam intervention strategies and programs aiming to reduce burden of multimorbidity should be directed more to rural areas. Further research should look at mode of delivery of health services to older people in the community setting and feasibility of methods of community based health promotion programs to reduce the burden of chronic disease among the older population. 


\section{Strengths and limitations}

The findings of our study are important given the lack of evidence study that adds more evidence to the literature on the burden of multimorbidity in Vietnam. This is also the first study reporting multimorbidity burden among older people in the Southern provinces of Vietnam including larger community based samples. Importantly the findings of this study are generalisable to the older population in Vietnam due to the use of cluster sampling and adjustment for under sampling of gender and place of residence.

Given that the medical personnel determined the presence of morbidity, the study is more reliable than those using self-reported data. Our study was restricted to six groups of conditions. Since the more chronic conditions that are included the more patients with multimorbidity will be found, the prevalence of multimorbidity in our study may be underestimated. Nonetheless, the six condition groups included all important chronic morbidities and since the pattern of multimorbidity observed were similar to those observed in many other studies we are confident that our study captured the majority of important multimorbidity.

This was a cross-sectional study, and thus causal relationships between independent variables and the prevalence of multimorbidity cannot be determined, rather evidence on prevalence and factors associated with the likelihood of multimorbidity have been evaluated. A strength of the study was our ability to report findings for both the univariate and multivariate models has also provided important evidence regarding stratified burden (univariate results) and independent associations (multivariate results) that are useful to health system policy makers.

\section{Conclusion}

The results of our study showed that multimorbidity are common among the older population of Southern Vietnam particularly in women and those of older age. Living in rural areas, being illiterate and not currently working were independently associated with multimorbidity. Those with multimorbidity were significantly more likely to have increased health service utilisation confirming the increased burden on health systems. The findings of our study indicate that intervention strategies and community based health promotion programs to reduce the burden of chronic disease among the older population should be directed more towards women and the elderly especially in rural areas.

\section{Competing interests}

The authors declare that they have no competing interests.

\section{Authors' contributions}

NTH was the principle investigator, responsible for fieldwork, analysed data; and wrote the draft of the manuscript with assistance of NHL, VK and RM. $\mathrm{NLH}$ advised on research design and revised the manuscript. VK and RM interpreted the findings and reviewed the manuscript. All the authors read and agreed on the views expressed in the manuscript.

\section{Acknowledgements}

The study was conducted with a financial support from World Health Organisation under project social determinant of health, a technical assistance from Dr Nhat Duc Phung, head of Community health department and social determinant network unit of Institute of Hygiene and Public health at Ho Chi Minh City. Data collection was performed with valuable contributions from data collectors and physicians working at commune health stations in the studied settings. We appreciate the time and valuable information provided by the respondents.

\section{Author details}

${ }^{1}$ Institute of Public Health, 159 Hung Phu Street, District 8, Ho Chi Minh City, Vietnam. ${ }^{2}$ School of Public Health, Curtin University, Bentley, Western Australia, Australia.

Received: 1 November 2014 Accepted: 22 May 2015

Published online: 30 May 2015

\section{References}

1. United Nations Population Fund (UNFPA) in Viet Nam. The ageing population in Vietnam: current status, prognosis, and possible policy responses. Vietnam: United Nations Population Fund (UNFPA); 2011.

2. le Hoi V, Phuc HD, Dung TV, Chuc NT, Lindholm L. Remaining life expectancy among older people in a rural area of Vietnam: trends and socioeconomic inequalities during a period of multiple transitions. BMC Public Health. 2009;9:471

3. Van Minh H, Lan Huong D, Bao Giang K, Byass P. Economic aspects of chronic diseases in Vietnam. Glob Health Action. 2009;2.

4. Hoy D, Rao C, Nhung NTT, Marks G, Hoa NP. Risk factors for chronic disease in Vietnam: a review of the literature. Prev Chronic Dis. 2013;10, E05.

5. le Hoi V, Chuc NT, Lindholm L. Health-related quality of life, and its determinants, among older people in rural Vietnam. BMC Public Health. 2010;10:549.

6. le Hoi V, Thang P, Lindholm L. Elderly care in daily living in rural Vietnam: need and its socioeconomic determinants. BMC Geriatr. 2011;11:81.

7. Van Minh H, Ng N, Juvekar S, Razzaque A, Ashraf A, Hadi A, et al. Self-reported prevalence of chronic diseases and their relation to selected sociodemographic variables: a study in INDEPTH Asian sites, 2005. Prev Chronic Dis. 2008;5:A86.

8. Marengoni A, Angleman S, Melis R, Mangialasche F, Karp A, Garmen A, et al. Aging with multimorbidity: a systematic review of the literature. Ageing Res Rev. 2011;10:430-9.

9. General Statistic Office. Result of the Vietnam household living standards survey 2010. In Book Result of the Vietnam household living standards survey 2010 (Editor ed.^eds.). City: General Statistic Office; 2010.

10. Health Service Delivery Profile, Viet Nam [http://www.wpro.who.int/ health_services/service_delivery_profile_vietnam.pdf]

11. Jerliu N, Toçi E, Burazeri G, Ramadani N, Brand H. Prevalence and socioeconomic correlates of chronic morbidity among elderly people in Kosovo: a population-based survey. BMC Geriatr. 2013;13.

12. Seal A, Branca F. Health and nutritional status of the elderly in the former Yugoslav Republic of Macedonia In Book Health and nutritional status of the elderly in the former Yugoslav Republic of Macedonia (Editor ed.^eds.) City: Institute of Child Health, London and National Institute of Nutrition, Rome; 2001.

13. WHO expert consultation. Appropriate body-mass index for Asian populations and its implications for policy and intervention strategies. Lancet. 2004:363:157-63.

14. van Oostrom SH, Picavet HS, de Bruin SR, Stirbu I, Korevaar JC, Schellevis FG, et al. Multimorbidity of chronic diseases and health care utilization in general practice. BMC Fam Pract. 2014;15:61.

15. Taylor A, Price K, Gill T, Adams R, Pilkington R, Carrangis N, et al. Multimorbidity - not just an older person's issue. Results from an Australian biomedical study. BMC Public Health. 2010;10:718.

16. Khanam MA, Streatfield PK, Kabir ZN, Qiu C, Cornelius C, Wahlin $\AA$ Prevalence and patterns of multimorbidity among elderly people in rural Bangladesh: a cross-sectional study. J Health Popul Nutr. 2011;29:406-14.

17. Marengoni AMDP, Winblad BMDP, Karp AP, Fratiglioni LMDP. Prevalence of chronic diseases and multimorbidity among the elderly population in Sweden. Am J Public Health. 2008;98:1198-200. 
18. Lawson KD, Mercer SW, Wyke S, Grieve E, Guthrie B, Watt GC, et al. Double trouble: the impact of multimorbidity and deprivation on preference-weighted health related quality of life a cross sectional analysis of the Scottish Health Survey. Int J Equity Health. 2013;12:67.

19. Agborsangaya CB, Lau D, Lahtinen M, Cooke T, Johnson JA. Multimorbidity prevalence and patterns across socioeconomic determinants: a cross-sectional survey. BMC Public Health. 2012;12:201

20. Foguet-Boreu Q, Violan C, Roso-Llorach A, Rodriguez-Blanco T, Pons-Vigues M, Munoz-Perez MA, et al. Impact of multimorbidity: acute morbidity, area of residency and use of health services across the life span in a region of south Europe. BMC Fam Pract. 2014;15:55.

21. Alaba O, Chola L. The social determinants of multimorbidity in South Africa. Int J Equity Health. 2013:12:63.

22. Banjare P, Pradhan J. Socio-economic inequalities in the prevalence of multi-morbidity among the rural elderly in Bargarh district of Odisha (India). PLoS One. 2014;9(6), e97832.

23. Schafer I, Hansen H, Schon G, Hofels S, Altiner A, Dahlhaus A, et al. The influence of age, gender and socio-economic status on multimorbidity patterns in primary care. first results from the multicare cohort study. BMC Health Serv Res. 2012;12:89.

24. Van Minh H, Huong D, Wall S, Chuc N, Byass P. Multilevel analysis of covariation in socioeconomic predictors of physical functioning and psychological well-being among older people in rural Vietnam. BMC Geriatr. 2010;10:7.

25. Adler NE, Newman K. Socioeconomic disparities in health: pathways and policies. Health Aff (Millwood). 2002;21:60-76.

26. Ross CE, Wu C. The links between education and health. Am Sociol Rev. 1995;719-745.

27. Violan C, Foguet-Boreu Q, Roso-Llorach A, Rodriguez-Blanco T, Pons-Viques $M$, Pujol-Ribera E, et al. Burden of multimorbidity, socioeconomic status and use of health services across stages of life in urban areas: a cross-sectional study. BMC Public Health. 2014;14:530.

\section{Submit your next manuscript to BioMed Central and take full advantage of:}

- Convenient online submission

- Thorough peer review

- No space constraints or color figure charges

- Immediate publication on acceptance

- Inclusion in PubMed, CAS, Scopus and Google Scholar

- Research which is freely available for redistribution 